\title{
Successful lung transplantation for talcosis secondary to intravenous abuse of oral drug
}

\author{
Dekel Shlomi' \\ David Shitrit' \\ Daniele Bendayan' \\ Gidon Sahar ${ }^{2}$ \\ Yitshak Shechtman ${ }^{3}$ \\ Mordechai R Kramer' \\ 'Pulmonary Institute, Departments \\ of ${ }^{2}$ Cardiothoracic Surgery \\ and ${ }^{3}$ Pathology, Rabin Medical Center, \\ Beilinson Campus, Petah Tiqwa, \\ and Sackler Faculty of Medicine, \\ Tel Aviv University, Tel Aviv, Israel
}

\begin{abstract}
Talcosis due to intravenous injection of oral drugs can cause severe pulmonary disease with progressive dyspnea even when drug use is discontinued. We describe a 54-yearold woman with severe emphysema who underwent left lung transplantation. The patient had a remote history of intravenous injection of crushed methylphenidate (Ritalin) tablets. Chest computed tomography showed severe emphysematous changes, more prominent in the lower lobes. Microscopic examination of the extracted lung demonstrated multinucleated giant cells with birefringent crystals, compatible with talcosis. At follow-up, daily symptoms were completely alleviated and lung function was good. We recommend that lung transplantation be considered as a viable option in the treatment of talcosis.
\end{abstract}

Keywords: methylphenidate (Ritalin), emphysema

\section{Introduction}

Talc, a hydrous magnesium silicate, is used as a lubricating and diluting substance in many oral medications, such as methadone, methylphenidate, and pentazocine. Intravenous abuse of these oral medications can cause talcosis. The talc crystals are filtered by the pulmonary vascular bed, forming foreign body granulomas within the alveolar capillary walls and perivascular area (Gibbs et al 1992). The talc particles deposited in the lungs following intravenous administration are larger than those observed for inhaled talc, and always contain particles that exceed $10 \mu \mathrm{m}$ (Feigin 1986). Progressive massive fibrosis (PMF) secondary to intravenous talc injection has been described with particles larger than $15 \mu \mathrm{m}$ were only found in the mass lesion (Crouch and Churg 1983). In contrast to intravenous administration, inhaled talc is usually accompanied by other minerals, such as silica or asbestos, and it is these that seem to have the prominent clinical, pathologic and radiographic effect in the lungs (Lockey 1981). In cases of talc inhalation, only small particles, usually measuring up to $5 \mu \mathrm{m}$, are filtered by the bronchial tree, reach the peribronchial and perivascular regions or forming intraalveolar talc and asbestos bodies (Katzenstein and Askin 1997). The early restrictive and obstructive features of talcosis due to intravenous use may progress to severe, sometimes fatal, pulmonary disease, even in patients who have discontinued use of the drug (Pare et al 1989).

Typical findings on computed tomography (CT) include large and irregular attenuated nodules ("ground glass") in the middle and upper part of the lung, which can evolve to large masses or massive consolidations (Feigin 1986). The presence of lower-lobe panacinar emphysematous processes is more common in methylphenidate abusers (Stern et al 1994; Ward et al 2000). Birefringent talc crystals can be identified under polarized light in tissue samples.

We describe a patient with severe emphysema due to pulmonary talcosis from intravenous methylphenidate abuse who underwent successful lung transplantation. We review the literature. 


\section{Case presentation}

A 54-year-old woman employed as a physiotherapist presented to our center in August 1999 with complaints of dyspnea. The diagnosis was emphysema. The patient had a history of heavy smoking (20-40 pack-years) until 1990 and of intravenous methylphenidate abuse for 4 years, 20 years previously. She also had rheumatoid arthritis treated with prednisone $7.5 \mathrm{mg}$ qd and positive serology for hepatitis $\mathrm{C}$, presently not active, with recent undetectable plasma RNA levels. Lung function test showed a forced expiratory volume in one second $\left(\mathrm{FEV}_{1}\right)$ of $28 \%$, forced vital capacity (FVC) 56\%, total lung capacity (TLC) $120 \%$, residual volume (RV) $242 \%$, and diffusing capacity for carbon monoxide (DLCO) $33 \%$ of predicted values. Treatment with salbutamol and ipratropium bromide inhalers was started.

Two years later, a significant deterioration was noted in the patient's functional capacity. She was unable to conduct activities of daily living and became oxygen-dependent. Physical examination revealed diffuse bilateral crackles on inspiration, predominantly in the lower lobes, without wheezing. Chemistry profile and blood count were within normal limits. Room air arterial blood gas demonstrated $\mathrm{pH}$ 7.43, partial pressure of carbon dioxide $\left(\mathrm{PCO}_{2}\right) 43 \mathrm{mmHg}$, and partial pressure of oxygen $\left(\mathrm{PO}_{2}\right) 65 \mathrm{mmHg}$. Resting oxygen saturation was $92 \%$ and decreased to $87 \%$ after a 1-minute walk. Chest X-ray film (Figure 1) demonstrated bullous emphysema and fibrotic changes, predominantly in the lower lobes. High-resolution CT of the chest (Figure 2) was consistent with emphysema, with marked hyperinflation of both lower lobes. In addition, bibasilar scarring involving mainly the right middle lobe and lingular segments was noted. There was no evidence of interstitial fibrosis.

Quantitative perfusion lung scan showed reduced perfusion to the lower lung zones with virtual lack of perfusion to the left lower lobe and to the lower third of the right lung. In the upper lung zones, the perfusion was mildly heterogeneous. Overall perfusion to the left lung was $41 \%$. Blood levels of C-reactive protein, alpha-1 antitrypsin, rheumatoid factor, antinuclear antibodies, antineutrophil cytoplasmic autoantibody and complement were within normal limits. Blood test for human immunodeficiency virus was negative. Findings on echocardiography were normal except for mild pulmonary hypertension, and heart catheterization demonstrated normal coronary arteries, pulmonary artery pressure of 40/13 mmHg (mean 29), and pulmonary wedge capillary pressure of $12 \mathrm{mmHg}$.

The patient was referred for lung transplantation, which was performed on December 15, 2003. In order to double

\section{A}
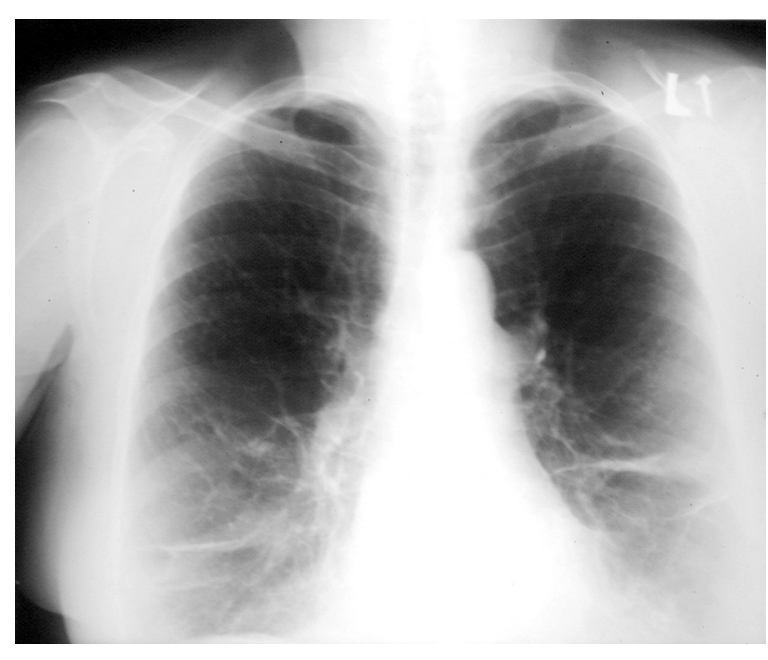

B

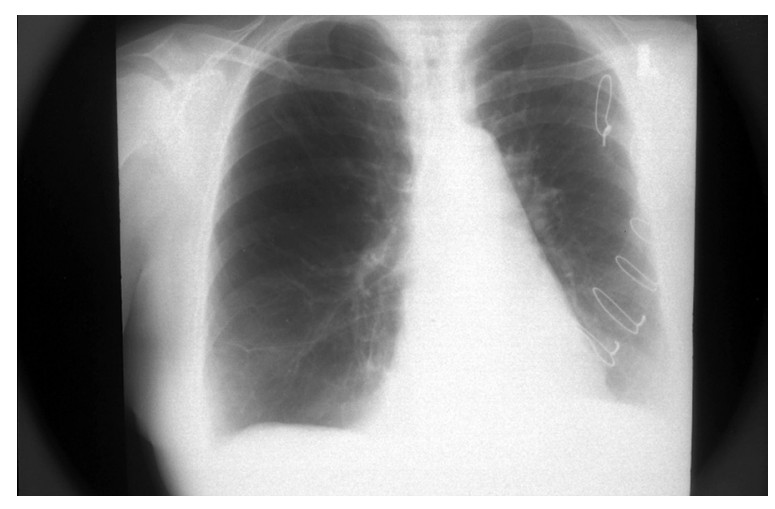

Figure I Chest X-ray film. A. Before transplantation, showing bilateral hyperinflation. Note also the increased interstitial marking and scarring in the basilar portions. B. Two months after left lung transplantation, showing well-inflated left lung.

our transplant recipients, we prefer conducting single lung transplantation in cases not involving chronic lung infections such as cystic fibrosis or bronchiectasis. We chose to conduct left lung transplantation in this patient according to the less perfused left lung (41\%). The transplantation procedure as well as the postoperative course were unremarkable, with no significant complications other than Nocardia pneumonia in the native lung, which resolved after a prolonged antibiotic course. A few months after transplantation, the patient resumed her normal activities. Oxygen saturation was normal on follow-up, with $\mathrm{FEV}_{1}$ ranging between $54 \%$ and $43 \%$ of predicted values. At the last visit, 3.5 years after transplantation, the patient was active and $\mathrm{FEV}_{1}$ was $49 \%$ of predicted on lung function test.

Pathologic examination of the extracted lung revealed macroscopic evidence of hyperinflation, with two lymph nodes showing hilar anthracosis. On microscopic examination (Figure 3), lymphocytic foci, congestion, and 


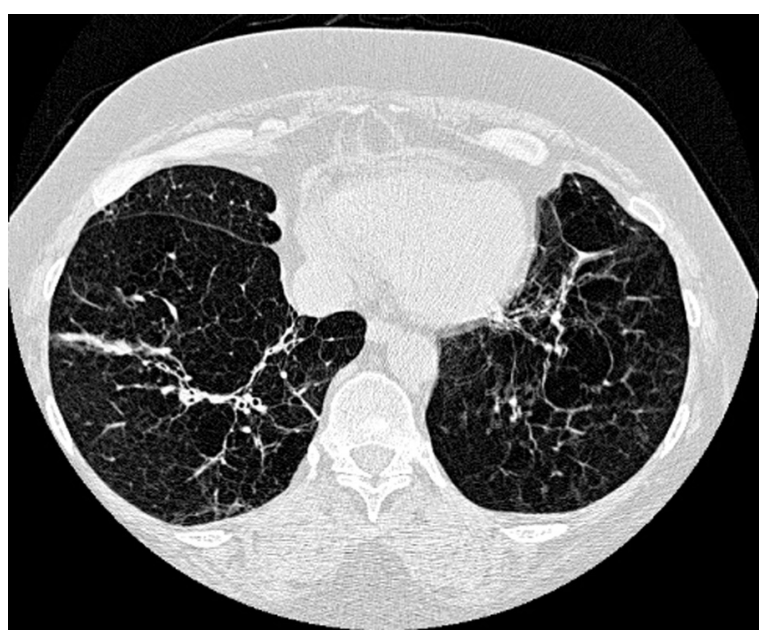

Figure 2 CT scan of the chest demonstrating severe emphysematous changes with bullous formation and scarring.

multinuclear giant foreign body cells with a foreign substance in their cytoplasm were seen. The foreign substance, which was birefringent under polarized light, measured at least 5-10 $\mu \mathrm{m}$, compatible with intravenously injected talc.

\section{Discussion}

Intravenous abuse of crushed oral medication can cause severe pulmonary disease. Pare and colleagues $(1979,1989)$ conducted a long-term follow-up of talcosis due to drug abuse of oral medication in 6 patients aged 23 to 51 years. All had severe progressive dyspnea despite their discontinuation of the drug. Chest radiographs revealed a gradual coalescence of nodules that eventually resulted in large, more or less homogeneous opacities in the perihilar and upper lobe regions. With time, hypertranslucency, oligemia, and bullae, mostly in the lower lung regions, became prominent. Pneumothoraces developed in 3 patients. Early pulmonary function tests demonstrated a combined restrictive and obstructive pattern, with no evidence of hyperinflation in most of the patients. However, long-term follow-up revealed rapidly progressive emphysematous features, namely, severe airflow obstruction, air trapping, and reduced diffusing capacity. Pathologic examination showed lung destruction, granuloma formation, and marked fibrosis. In a similar study, Sieniewicz and Nidecker (1980) described 4 patients with conglomerate pulmonary disease associated with intravenous injection of crushed methadone tablets. Chest X-ray film showed a micronodular pattern in 3 cases which later blended into masses in the upper lobes. The remaining patient had mediastinal adenopathy followed by the development of bilateral pneumothoraces.
The patient described here had progressive dyspnea despite discontinuation of drug abuse. Her lung functions were compatible with severe emphysema, and chest CT revealed an emphysematous pattern in the base of the lung but without nodules or masses and no evidence of interstitial fibrosis. Although the patient had a past history of cigarette smoking, we would have expected emphysema in the upper lung zones had cigarettes been the cause. Alpha-1 antitrypsin deficiency, which can also cause lower-lobe emphysema, was ruled out by normal blood levels. In our patient, the lower lobe emphysema seemed to be compatible with her history of talc injection.

Our review of the literature yielded 2 cases of lung transplantation in patients with pulmonary talcosis secondary to intravenous drug abuse. In the case described by Cook and colleagues (1998), the pulmonary talcosis recurred 18 months following single-lung transplantation. After the transbronchial biopsy showed evidence of talcosis in the transplanted lung, the patient, a 48-year-old former

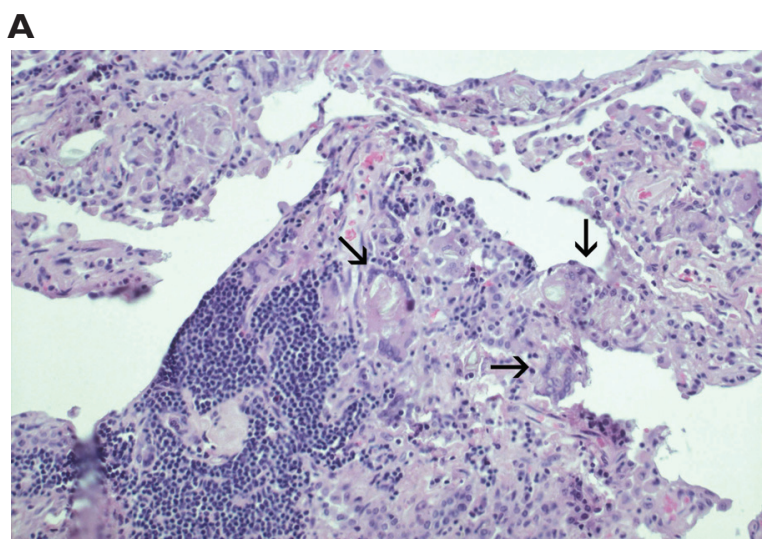

$\mathbf{B}$

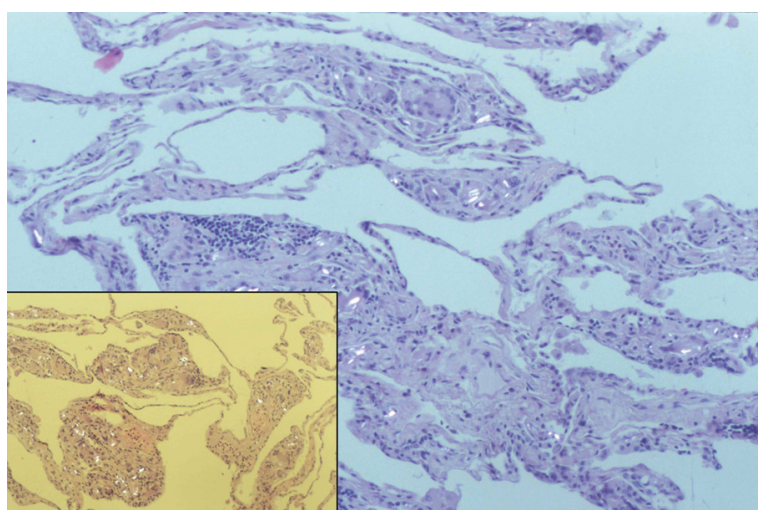

Figure 3 Pathologic study of the extracted lung. A. Note focal interstitial lymphocytic infiltrates (lower-left field) and giant foreign cells (arrows) with evidence of foreign material in the cytoplasm (hematoxylin-eosin; magnification $\times 200$ ). B. Polarized particles in the interstitium and cytoplasm of the giant cells can be seen (magnification $\times 100$ ) 
intravenous methylphenidate abuser, admitted to recurrent intravenous drug abuse. The second patient was one of a series of intravenous oral drug abusers described by Stern and colleagues (1994). The patient underwent single-lung transplantation for basilar emphysema caused by intravenous injection of crushed methylphenidate tablets. The extracted lung was examined pathologically, but the authors provided no clinical data on this case. Recently, Fields and colleagues (2005) described a 24-year-old woman after bilateral lung transplantation for cystic fibrosis in whom microcrystalline cellulose embolization was detected on routine transbronchial biopsy. The patient admitted injecting crushed promethazine tablets through her intravenous port in order to control severe nausea caused by cytomegaloviral gastritis. She had no history of intravenous drug abuse, and histological examination of her native lungs was negative for intravascular or parenchymal foreign material.

Organ transplantation in substance abusers is controversial because of the possibility of relapse, even in those after long-term abstinence. Most of the information on this issue derives from studies of patients with alcoholism, also associated with a high relapse rate. The emerging data favor performing liver transplantation in selected patients after careful psychological evaluation since only few patients will resume heavy drinking after the transplantation (DiMartini et al 2002). In patients with drug-induced talcosis, clinicians should bear in mind that the dose-injury relationship has not yet been established.

Our patient was referred for single-lung transplantation because of severe emphysema mainly in the lower lobes. Her symptoms were completely alleviated by the procedure. Her intravenous use of crushed methylphenidate tablets in the past together with the normal blood alpha-1 antitrypsin levels indicated a diagnosis of lower-lobe emphysema secondary to talcosis. Pathologic examination of the extracted lung revealed the characteristic evidence of talcosis consequent to intravenous injection of talc.

We conclude that the mid-term outcome of lung transplantation in patient with talcosis is similar to that for other diagnoses. We recommend that lung transplantation be considered as a viable option in the treatment of talcosis. However, candidates should undergo a comprehensive psychiatric assessment to minimize the risk of recurrence of substance abuse after treatment.

\section{References}

Cook RC, Fradet G, English JC, et al. 1998. Recurrence of intravenous talc granulomatosis following single lung transplantation. Can Respir J, 5:511-14.

Crouch E, Churg A. 1983. Progressive massive fibrosis of the lung secondary to intravenous injection of talc. A pathologic and mineralogic analysis. Am J Clin Pathol, 80:520-6.

DiMartini A, Weinrieb R, Fireman M. 2002. Liver transplantation in patients with alcohol and other substance use disorders. Psychiatr Clin North Am, 25:195-209.

Feigin DS. 1986. Talc: understanding its manifestations in the chest. $A m J$ Roentgenol, 146:295-301.

Fields TA, McCall SJ, Reams BD, et. al. 2005. Pulmonary embolization of microcrystalline cellulose in a lung transplant recipient. J Heart Lung Transplant, 24:624-7.

Gibbs AE, Pooley FD, Griffiths DM, et al. 1992. Talc pneumoconiosis: a pathologic and mineralogic study. Hum Pathol, 23:1344-54.

Katzenstein A-LA. 1997. Katzenstein and Askin's Surgical Pathology of Non-Neoplastic Lung Diseases, vol 13, 3rd ed. Philadelphia, PA: W.B. Saunders Company, pp. 130-1.

Lockey JE. 1981. Nonasbestos fibrous minerals. Clin Chest Med, 2:203-18.

Paré JP , Cote G, Fraser RS. 1989. Long-term follow-up of drug abusers with intravenous talcosis. Am Rev Respir Dis, 139:233-41.

Paré JA, Fraser RG, Hogg JC, et al. 1979. Pulmonary 'mainline' granulomatosis: talcosis of intravenous methadone abuse. Medicine (Baltimore), 58:229-39.

Sieniewicz DJ, Nidecker AC. 1980. Conglomerate pulmonary disease: a form of talcosis in intravenous methadone abusers. Am J Roentgenol, 135:697-702.

Stern EJ, Frank MS, Schmutz JF, et al. 1994. Panlobular pulmonary emphysema caused by i.v. injection of methylphenidate (Ritalin): findings on chest radiographs and CT scans. Am J Roentgenol, 162:555-60.

Ward S, Heyneman LE, Reittner P, et al. 2000. Talcosis associated with IV abuse of oral medications: CT findings. Am J Roentgenol, 174:789-93. 
